\title{
TRANSIENCY, FLY-IN-FLY-OUT WORKERS, AND SUSTAINABILITY: PERCEPTIONS FROM WITHIN A RESOURCE-BASED COMMUNITY
}

\author{
LEITH DEACON, JACOB W. PAPINEAU \& TRINA LAMANES \\ Department of Earth \& Atmospheric Sciences, The University of Alberta, Canada
}

\begin{abstract}
The dynamics of the modern workforce required for large industrial development has changed over the last several decades. More specifically, many companies based in oil and gas extraction are opting to adopt a fly-in-fly-out (FIFO) workforce model, in particular those based on the extraction and production of oil and gas, in an attempt to minimize infrastructure costs and alter the cyclic boom/bust nature associated with resource extraction. Employing semi-structured interviews with key informants from Fort McMurray, Alberta, perhaps the most notorious resource-based community in Canadian history, this paper details how residents perceive the FIFO workers and what impacts this new employment strategy may have on their community. The primary findings indicate that while it is necessary to have access a large workforce, the use of FIFO workers negatively impacts the local community in several ways. First, the use of FIFO workers not only reduces the interaction that employees have with the nearby community, but alters their perception of that community. Second, FIFO workers access local infrastructure (e.g. healthcare) but do not support further development through taxes and discretionary income. Third, the transiency of FIFO workers affects place-attachment and long-term sustainability of the region. This research contributes to existing literature on resourcebased communities, sustainable urban development, and FIFO employment through use of a Canadian case-study that illustrates local experiences of the impacts of a relatively new employment model that has the potential to significantly impact resource-based communities.
\end{abstract}

Keywords: resource-based communities, sustainability, planning, resiliency, recreation, leisure, Canada, fly-in-fly-out.

\section{INTRODUCTION}

Sites for industrial development, in particular those based on the extraction and production of oil and gas, require a large accessible workforce and traditionally result in the growth of existing rural communities and development of new suburbs [1]-[3]. These communities, referred to as 'boomtowns' or resource-based communities (RBCs), experience considerable and rapid economic and population growth (or decline) due to the extraction of a natural resource [2]-[4]. To minimize significant development costs and temper the cyclic boom/bust nature of resource development economics, many companies based in extractive industries are adopting a fly-in-fly out (FIFO) workforce model to increase flexibility in meeting labor needs. This model involves flying employees to worksites for set-duration shifts and then flying them back to their home locations, rather than relocating employees and their families to towns proximate to the work site. Significant academic attention has focused on the culture of FIFO; however, little empirical work has investigated residents' perceptions from nearby towns about how a mobile FIFO workforce affects them and their community.

Using Fort McMurray, Canada as a case study, this paper links two areas of academic inquiry. First, it contributes to literature on resource-based communities by exploring how residents from within a traditional RBC perceive changes in the employment landscape (i.e. FIFO workers). Second, it contributes to the socially sustainable urban planning and development literature by detailing residents' experiences of the 'fly-over-effect' associated 
with the FIFO workforce and how this change has affected their community. We emphasize important aspects to be considered by all-levels of government(s) when developing policy around sustainable extraction practices. We do this by recounting the experiences of residents from Fort McMurray, Canada's most notorious RBC. To set the stage for the study, we briefly review the academic literature on RBCs, the FIFO workforce model, and socially sustainable urban planning and development.

\subsection{Resource-based communities}

Previous research characterizes resource-based communities (RBCs) as primarily small, homogenous, rural communities that have undergone an unprecedented phase of economic and population growth due to the extraction of a natural resource [2]-[6]. While the term 'boomtown' may evoke images of historical mid-19th century mining towns in the western United States, RBCs are also conceptualized as a material expression of general processes fueled by speculation over a potential source of vast wealth, which varies based on the valued resource and time period [7]. Significant attention has focused on the environmental impacts of resource extraction, yet there is increasing interest on the impacts to social systems within RBCs. Industrial activity associated with the extraction of natural resources attracts an initial influx of people seeking employment opportunities [8]. This rapid population growth often strains urban services (e.g. health care, schools, childcare, and retail) and local infrastructure (e.g. transportation and housing) beyond regional capacity to meet supply [9]. Research has demonstrated there are many interrelated social impacts that occur within RBCs from this rapid growth including social disruption, transiency, inflated housing costs, insufficient urban infrastructure and services, and a lack of a sense of community or social cohesion, which further limits the ability of these communities to attract permanent residents [2], [9]-[13].

\subsection{Fly-in-fly-out workforces}

Boomtowns in the early 20th century were male-dominated work places commonly associated with lawless incorrigible behavior [7], with social problems and instability attributed to a largely male workforce being away from their partners and families [1]. Beginning in the mid-1950s, industry sought to establish more permanent settlements, referred to in the literature as 'company towns', to supply housing for a resident workforce and their families proximate to extraction sites [1], [12], [14].

These 'company towns' were essentially owned and operated by industry and were designed to provide accessible, affordable housing for workers. Greater housing accessibility provided workers with opportunities to bring their families, helping to ease some of the negative social conditions that affected worker health and productivity. However, industryrun 'company towns' often struggled to provide adequate urban services for residents. To address persistent resident instability resulting from inadequate services, the incorporation of 'company towns' as independent municipalities emerged with varying degrees of success [1].

In response to the challenges of providing housing for the influx of workers, industry increasingly supports the use of temporary camp-like accommodations for non-resident workers. This 'camp model' is fundamentally different from the 'company town' development model, as workers are flown to the worksite and housed in temporary structures located near-site for the duration of their shifts and then are flown back home. Known more commonly as 'fly-in-fly-out' (FIFO) communities, the 'camp model' is commonly used by industry to alleviate stress on local housing markets in RBCs and to provide access to a larger workforce in a flexible and cost-effective manner [12], [14]-[16]. FIFO accommodations 
provide many of the physical and social needs for workers while they are in camp to support their well-being and productivity. However, the 'camp model' is not conducive to the development of social cohesion or bonds because FIFO accommodations are often geographically and socially removed from the larger community [8], [14], [16]. This isolation creates a 'fly-over-effect' whereby money earned by workers is not spent in the local community to support a developing retail and service sector such as dining and entertainment, recreation, and local food producers [14].

\subsection{Socially sustainable urban development}

Sustainable urban development has various meanings that are applicable to environmental, economic, and social systems. These systems comprise a three-pillar model of "complex interdependencies" [17, p. 3] that often have competing agendas and various interpretations that can make sustainable urban development a difficult, if not contradictory, endeavor. Taking a geographic perspective, sustainable urban development focuses on how these three pillars (i.e. environment, economy, society) interact within urban space to provide a high quality of life for residents. Meeting social and economic needs within an urban environment that continually requires sources of energy, without causing environmental harm, is the primary goal of sustainable urban development [18].

Recent research prioritizing the creation of responsive and adaptive policies to support sustainable urban development has focused on the social dimensions of development [19][21]. Various contextual specificities affect communities and their residents. There are many factors that residents consider during their assessment of community life and conditions that support retention and social sustainability include opportunities for social interaction, community cohesiveness, group decision making, open space, and topography [22].

\section{CASE STUDY}

\subsection{Background}

This case study is part of a larger project investigating sustainable urban planning development in RBCs across Canada. The case study outlined here emerged as part of our interpretation of participant interviews, in combination with existing literature(s). That is, literature on RBCs was our starting point, but themes identified within the case study led us to emphasize the perception of residents from an $\mathrm{RBC}$ regarding a relatively new change in the workforce: fly-in-fly-out workers. We identified this theme post hoc-a common strategy to avoid premature interpretive closure in qualitative research [23], [24]. Our objective is to understand how residents of a near-by community impacted by the extractive activities that surround it perceive workforce mobility changes resulting from the use of FIFO workers.

\subsection{Case community}

The Regional Municipality of Wood Buffalo (RMWB), located in north-eastern Alberta (see Fig. 1) Canada, incorporates a geographic area of over 63,000 kilometers, making it one of the largest municipalities in North America [25].

Comparatively, the region is more than twice the size of Belgium and nearly as large as Scotland. The region encompasses ten rural communities and one urban service center in the heart of the boreal forest, surrounded by wetlands and numerous river systems that provide the region with accessible natural amenities. Fort McMurray is the urban service center and is approximately 435 kilometers north of the nearest major city and Provincial capital, 
Edmonton. Two major highways provide access to the RMWB. Over the past decade the provincial government has invested a significant amount of money to improve local road infrastructure, including the twinning of major Highway 63, completed in 2016 [26]. This investment was justified to expand oil sands operations and improve the safety of the highway.

In response to the challenges of providing housing for the influx of workers, industry increasingly supports the use of temporary camp-like accommodations house the region's 'unofficial population' - non-resident temporary workers [27]. Historically, the municipality has had difficulty in determining accurate population numbers due to this shadow population. For example, in 2012 the official 'shadow population' of 30,271 was believed to be much lower than the actual population based on municipal water usage rates for the camp accommodations, which reflected a population size of approximately 82,374 [27]. The significance of this is that such a large, dynamic undocumented population can greatly impact the planning and provision of appropriate urban and rural services in this region.

As of the last official census report in 2015 , the population of the region was 125,032 , which is an increase of 8,625 from the 2012 census. This includes Fort McMurray $(78,382)$, the rural service area $(3,566)$, and non-permanent residents including camp accommodations $(43,084)[27]$.

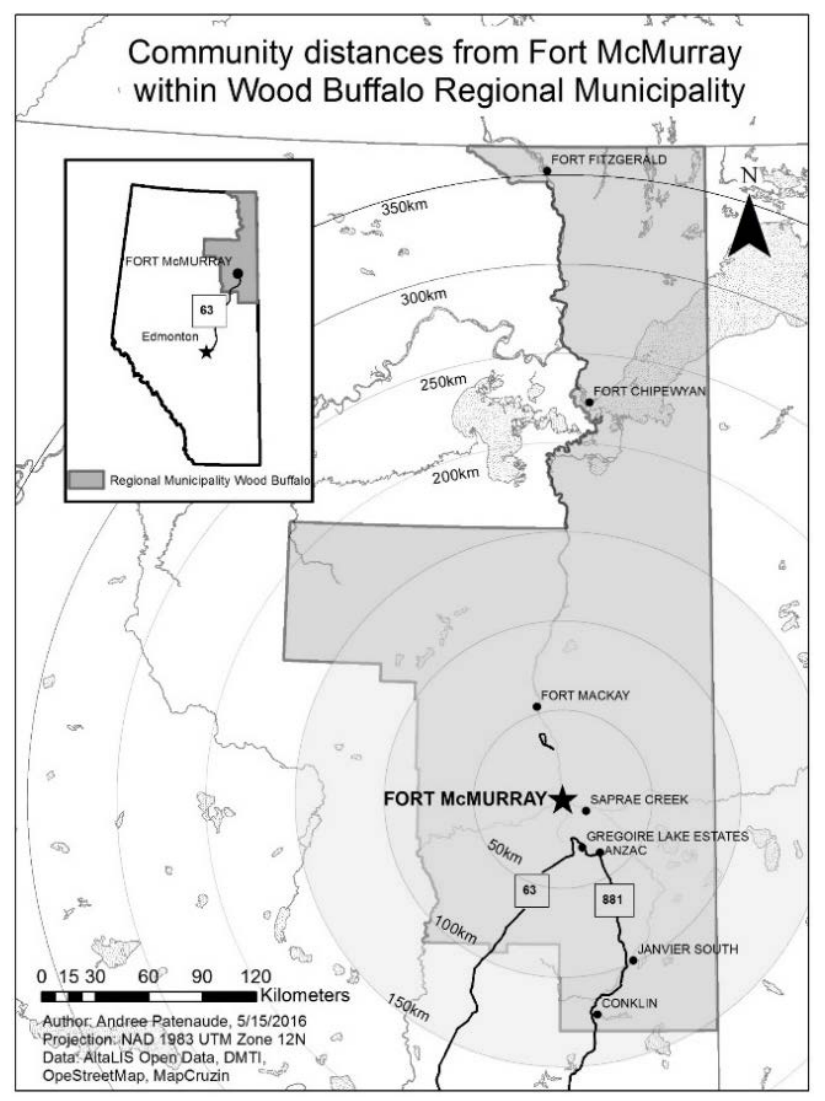

Figure 1: Regional municipality of Wood Buffalo, Alberta, Canada. 


\section{METHODOLOGY}

Twenty-five residents from Fort McMurray $(\mathrm{N}=25)$ participated in semi-structured interviews. Arbitrarily, the selection process resulted in ten males and fifteen female participants.

Interviews were conducted in locations of the participants choosing (e.g. place of work, home, restaurant) and lasted between 60 to 90 minutes in length. An interview guide was developed based on background information gathered from an analysis of relevant planning documents and government reports. In advance of the interview, participants received a written description of the research and consent form via email. Participants were asked if they had any questions before interviews began and signed a consent form to indicate their understanding of the research process and willingness to participate.

\subsection{Participant selection}

Using purposive sampling, initial participant selection targeted two viewpoints: municipal and industry interests. Once initial contact was made, we selected subsequent participants using snowball sampling until we obtained a satisfactory level of saturation. As snowball sampling often relies on participants sharing contacts that may hold similar values [28], maintaining two separate participant streams allowed us to access a wider-range of perspectives. During the iterative process of collecting and analyzing interview data, we identified additional participants based on the observations and experiences of those participants interviewed. Of the twenty-five participants interviewed, twenty-eight percent $(\mathrm{N}=7)$ had lived in the RMWB for less than 5 years, forty-four percent $(\mathrm{N}=11)$ had lived there for more than ten years, and twenty-eight percent $(\mathrm{N}=7)$ had lived in the region for more than 20 years. Sixteen of the participants were Canadian: four from Eastern Canada ${ }^{1}$, four from Eastern-Central Canada ${ }^{2}$, five from the Prairies ${ }^{3}$, and three from Western Canada ${ }^{4}$. Nine of the participants had emigrated to the RMWB from other countries: two from India, two from England, one from the Czech Republic, two from Nigeria, and two from Colombia. While this method of participant selection is not considered a representative sample of the ethnic variability within the RMWB, it provided views from as many groups as the interview data support. Upon reaching theoretical saturation, no additional participants were sought [29].

\subsection{Planning documents}

To establish necessary context and relevant background information for the semi-structured interviews, a review of municipal planning documents and Provincial government reports was conducted. The document analysis highlighted the particular values and practices of urban development planning within the RMWB's institutional frameworks and informed the initial development of the interview guide. In addition to informing the interview guide, analyses of municipal [27] and Provincial documents [29] provided insight into some of the challenges and concerns of retaining a permanent resident population not revealed through

\footnotetext{
${ }^{1}$ Eastern Canada includes the Provinces of Nova Scotia, Newfoundland \& Labrador, Prince Edward Island, and New Brunswick.

${ }^{2}$ Eastern-Central Canada includes the Provinces of Ontario and Quebec.

${ }^{3}$ The Prairies include the Provinces of Manitoba, Saskatchewan, and Alberta.

${ }^{4}$ Western Canada includes the Province of British Columbia.
} 
interview data alone. The background contained in these various documents helped us to develop relevant questions that participants would find interesting to discuss.

\subsection{Data analysis method}

This case study employs discourse analysis as a primary data analysis method. Discourse analysis allows the researcher to understand the meanings behind the words of the participants, which reflect the social process or phenomenon under study. This meaning becomes a co-construction between the researcher and participant in an iterative process of clarifying and confirming the meaning of the words used by both participant and researcher during the interview. Discourses shaped or constructed by those people who are experiencing the phenomena under study may not be understood outside of the social context (the RBC) and the co-construction process provides an agreed upon portrayal of the phenomena.

\section{RESULTS}

Three themes emerged from the interview data: (1) Stereotypes: participants expressed concerns over the potential negative stereotypes perpetuated by FIFO workers; (2) Infrastructure: residents were critical of the impact of FIFO workers on municipal infrastructure when the majority of their tax dollars did not go to the municipality; and, (3) Place Attachment: participants were critical of FIFO workers and their lack of interaction with the community-at-large potentially impacting their attachment to the Municipality.

\subsection{Stereotypes}

Participants $(\mathrm{N}=25)$ identified challenges related to the nature of the oil and gas industry and felt that the fly-in-fly out (FIFO) workers presented an inaccurate representation of the community. Common sentiments amongst participants were that FIFO workers enhanced the reputation of the RMWB as unattractive, as FIFO workers were reluctant to bring their families and consider permanent residency in the region. Anna, a resident for over 10 years, conveys the opinions she has heard in the community:

"I know a lot of people say we gotta stop the fly-in-fly-out kind of thing so if people are moving up here with their families and being part of the community then they will have those social networks they need to sustain them through some of this stuff. A lot of times the camp workers have a negative impression of Fort McMurray but they never get to see the good part of it because they're at the camp."

Will, a longtime resident of Fort McMurray, also expressed that he felt that camp workers perpetuated a negative perception of life in RMWB. For example, he noted that the money made by FIFO workers is not spent in the community, hindering the development of a more diversified local economy that could provide a variety of opportunities to improve the community:

"They're the ones that every word is the ' $\mathrm{f}$ ' bomb when they talk about Fort McMurray and talk about how horrible it is, and how much they hate it here but they love payday and they love that flight back home to spend all their money!"

Generally, participants' comments regarding the negative impacts of FIFO lifestyles to local community life included consistent references to leisure and recreation, road construction, and reduced health care. These concerns reflect various aspects of frustration that has created a division between residents and non-residents. Participants complained that 
FIFO workers, often referred to as 'camp workers', use the regions' public infrastructure and 'take from the community' but felt that they (the FIFO workers) did not contribute back to, or invest in the community.

\subsection{Infrastructure}

Comments were often emotionally charged regarding the strain on infrastructure caused by FIFO workers. The impact the 'shadow-population' has on existing infrastructure was a common theme throughout the interviews. Dan, a resident of approximately 5 years, points out that the infrastructure extends to the smaller communities in the RMWB where many new oil sands plants are expected to increase the FIFO population:

"Ok. So now you got a population of 72,000 [urban service center] people or 108,000 [entire region]. Oh, we haven't talked about the work camps either so let's throw another 40-50 thousand out there. Why do we have to consider them? Because most of them are up here [Fort McMurray] some of them are down in Conklin area, either way they're using the infrastructure. So, what do you build for capacity here right?"

Alex, who works in the emergency department of the local hospital, notes that apart from accessing public infrastructure, FIFO workers are largely absent in terms of community involvement with residents. Thus, there is a common sentiment that FIFO workers are not considered part of the community:

"The transient or the majority of those camp workers, they won't see the community unless they come in to get drunk or go to the hospital. So, they just come in to take from our system they don't contribute to our system."

John has lived in the RMWB for a short time, but he has also observed there are fly-over impacts from FIFO practices:

"It would be helpful absolutely! It would be helpful to keep some money in this community as opposed to just taking the money away and spending it elsewhere."

The fly-over effect from the highly mobile workforce associated with the oil and gas industry was felt to negatively impact commercial development. Dale reflected on the fact that people tend to stay here for a short duration. His silence indicates that an unstable consumer base is unattractive for commercial development:

"With so much focus on the energy sector we're definitely lacking the [pause] in that department [retail]. But I think that again given the fact that most people stay here for two years. Two years you know [pause] sooo..."

\subsection{Place attachment}

A significant number $(\mathrm{N}=14)$ of participants expressed that the FIFO lifestyle reduced the potential to develop place attachment. Participants felt that the lack of a social support system and primary focus on work increased feelings of loneliness and stress amongst many camp workers who then associate this experience with the whole community. Brad's perspective considers that FIFO workers have simply not experienced what the community of Fort McMurray can offer them:

“And then we have a work camp population [pause] they couldn't even tell you where McDonald Island is. And that's ok there's nothing wrong with it... it's not a value 
judgment that I'm making. They never come in town. You have 90,000 people living a 'normal residential life' and you have 30,000 people living in camps, many of whom will actually never experience the actual community, and have whatever opinion they have based on that experience. So, a lot of what you hear from a reputational point of view is. "I hate Fort McMurray! I go there to work, it sucks". Well yeah you live in a dorm. It's isolated its dark and its cold and you have no friends and you have no family and all you're doing is making money and sending it back somewhere ...of course it sucks."

Participants also acknowledged that camp workers were not entirely to blame for the lack of social interaction. Dale, a municipal employee and industry relations liaison, explained that often camps are located too far away for workers to come into the city on a regular basis. He explained that improving camp workers' perceptions of the RMWB community requires a concerted effort:

"If they're close enough, camps have buses bring'em in to town so the guys can go to a movie, go the doctor go to a restaurant or do whatever it is that they want to do. Um... but again it's just back to that piece about changing perception. They're probably not gonna spend, what there's forty some odd thousand people that live in camps throughout the region, there's a good chance that most of them aren't ever gonna come into Fort McMurray, they might see the airport. So, give them as much information about Fort McMurray and then when they are here make sure they have a good [pause] whatever you can do to make sure they have a good experience when they are here."

Anna, involved with the capacity building of community's social profits (non-profit and social service) at the time of the interview, corroborated the sentiment that it is not necessarily a choice amongst FIFO workers to not participate in community activities:

"Like, I think a lot of the camp jobs they work 21 days then they go back to where they came from for 7. So yeah, they don't see a lot of Fort McMurray. They don't have a chance to participate in anything."

While they understood that work camps have been a necessary part in the development of the oil sands, many participants $(\mathrm{N}=8)$ felt that there was a responsibility for employers to encourage and ensure that workers get involved in the community. Will, a semi-retired homebuilder, requires that his employees live in the community because he feels that they will conduct themselves better and become more invested in their workmanship. While he recognizes this was mainly for his benefit in maintaining his company's reputation, he also recognizes there was a spillover effect into the community:

"I hate this whole camp bullshit. If I could eliminate and say if you're working here you have to be here. I won't hire... I've had my company for 17 years and I absolutely refused to hire anyone who was just here to earn their stamps or if someone asks me is there a camp arrangement I say no. I'm looking for people who are in the community or want to be in the community I have no desire to talk to you outside of that. And you know again the people that are only here to make that buck and get out they just have a bad attitude and that's reflected in what they do every day what they say and how they carry themselves and how energetic they are... it's just your happier when your home. So, if you make it home you tend to be happier. If you're living in camp or someone's basement or boarding out a room and sending your check home or whatever how can you be happy? How is that a good life?" 


\section{DISCUSSION \& CONCLUSIONS}

Before addressing the findings related specifically to perceptions held by residents from an RBC about FIFO workers, it is important to note that participants were supportive and proud of their community. This project illustrates that there are prevailing themes of support, resiliency, and social cohesion amongst residents within the RMWB (excluding the shadow population). These findings demonstrate that the population has strong social bonds, which is contrary to what is expected in an RBC according to academic literature [9]-[12]. One of the most significant contributing factors to the sense of community expressed by participants was the common experience of being from somewhere else. From this experience, residents are able to relate to one another and understand some of the difficulties others may be having due to being away from family and friends. Residents can bond based on this common experience so much so that the majority of participants expressed that in the RMWB "your friends become your family".

While there is no objectively measured data available for the rates of transiency in the RMWB, the perception amongst participants is that it is highly transient and common to reside in the community for two or five years. This has negative impacts (e.g. social isolation, reduce social cohesion) on the community, echoing previous research in RBCs [2], [9]-[12]. FIFO workers, who are typically housed in camp accommodations, often never take the opportunity to travel into the urban service center and experience what amenities Fort McMurray and the region offers. The significance of this is twofold: large numbers of workers are not engaged with the community and worker discretionary income is spent outside of the community. This is referred to as the fly over effect [4]. A central challenge to sustainable urban development in the RMWB is to accommodate the necessary workforce for the oil sands and integrate non-resident workers into the community, regardless of their propensity or willingness for permanent residency. Providing non-resident workers opportunities to establish a sense of attachment to the local community can increase instances of positive experiences through civic responsibility and involvement that is needed to alleviate many of the social problems found in RBCs [31]. A sense of place attachment "develops through an interconnectedness of the social to the physical" that occupy the same space [32, p. 1].

Finally, the media often targets non-resident/FIFO workers for interviews about what it is like to work and live in the RMWB. These interviews perpetuate a sense of notoriety about the region that may present an inaccurate snapshot of local conditions. A key factor influencing the perceptions of FIFO workers is inadequate social infrastructure for this large portion of the population (approximately 32 percent). Ensuring equitable access to such infrastructure requires active cooperation between municipal planners and industry on how to develop flexible policy and practices to allow workers the ability to experience social spaces and incentivize them to settle permanently in the RMWB. This approach goes against the premise of FIFO practices that claim it is a viable solution to supply industrial projects with a productive workforce [14]-[16]. As reflected in the sentiments expressed by interview participants, a sense of social cohesion exists within the RMWB that may allow for greater integration if FIFO workers are provided with more opportunities to participate in the community, developing a sense of place attachment in the process. Attracting and retaining a permanent resident workforce in the RMWB will benefit industry by providing a stable and accessible workforce, as well as the RMWB community itself by retaining the long-term, permanent residents necessary to achieve sustainable urban development and economic diversification. 


\section{REFERENCES}

[1] Gill, A. M., An Evaluation of Socially Responsive Planning in a New Resource Town. Social Indicators Research, 24(2), pp. 177-204, 1991.

[2] England, J. \& Albrecht, S., Boomtowns and social disruption. Rural Sociology, 49(2), pp. 230-246, 1984.

[3] Freudenburg, W., Women and Men in an Energy Boomtown: Adjustment, Alienation and Adaptation. Rural Sociology, 46(2), pp. 220-244, 1981.

[4] Besser, T., Miller, N. \& Malik, R., Community Amenity Measurement for the Great Fly-Over zones. Social Indicators Research, 106(2), pp. 393-405, 2012.

[5] Papineau, J.W. \& Deacon, L., Fort McMurray and the Canadian Oil Sands: Local Coverage of National Importance. Environmental Communication, Advance online publication 2017. doi:10.1080/17524032.2017.1289107.

[6] Deacon, L. \& Lamanes, T., Resiliency and resource-based communities: A Canadian case study. In Ozcevik, O., Brebbia, C.A. \& Sener, S.M. (Eds.). Sustainable Development and Planning VII, pp. 713-736, WIT Press: London, UK, 2015.

[7] Hostetter, E., Boomtown Landscapes. Material Culture, 43(2), pp. 59-79, 2011.

[8] Halseth, G. \& Doddridge, J., Children's Cognitive Mapping: A Potential Tool for Neighborhood Planning. Environment \& Planning B: Planning \& Design, 27(4), pp. 565-582, 1999.

[9] Lawrie, M., Tonts, M. \& Plummer, P., Boomtowns, Resource Dependence and SocioEconomic Well-Being. Australian Geographer, 42(2), pp. 139-164, 2011.

[10] Ennis, G., Finlayson, M. \& Speering, G., Expecting a Boomtown? Exploring Potential Housing Related Impacts of Large Scale Resource Development in Darwin. Journal of Studies and Research in Human Geography, 7(1), pp. 33-42, 2013.

[11] Franks, D., Social Impact Assessment of Resource Projects. International Mining for Development Centre, 2012, Online.

http://im4dc.org/wp-content/uploads/2012/01/UWA_1698_Paper-02_Social-impactassessment-of-resource-projects1.pdf

[12] Carrington, K. \& Pereira, M., Assessing the Social Impacts of the Resources Boom on Rural Communities. Rural Society, 21(1), pp. 2-20, 2011.

[13] Knox, P.L., Social Well-Being and North Sea Oil: An Application of Subjective Social Indicators. Regional Studies: Journal of the Regional Studies Association, 10(4), pp. 423-432, 1976.

[14] McKenzie, F., McKenzie, H.F. \& Hoath, A., Fly-In/Fly-Out, Flexibility and the Future: Does Becoming a Regional FIFO Source Community Present Opportunity or Burden? Geographical Research, 52(4), pp. 430-441, 2014.

[15] Perring, A., Pham, K., Snow, S. \& Buys, L., Investigation into the Effect of Infrastructure on Fly-In-Fly-Out Mining Workers. Australian Journal of Rural Health, 22(6), pp. 323-327, 2014.

[16] Storey, K., Fly-in/Fly-out and Fly-over: Mining and Regional Development in Western Australia. Australian Geographer, 32(2), pp. 133-148, 2001.

[17] Elliott, J.A., Sustainable Development. In Kitchin, R. \& Thrift, N. eds. International Encyclopedia of Human Geography, 1, pp. 117-131, Elsevier Science: Atlanta, USA, 2009.

[18] Whitehead, M., Urban Sustainability. In Kitchin, R. \& Thrift, N. eds. International Encyclopedia of Human Geography, 1, pp. 109-116, Elsevier Science: Atlanta, USA, 2009. 
[19] Weingaertner, C. \& Moberg, Å., Exploring Social Sustainability: Learning from Perspectives on Urban Development and Companies and Products. Sustainable Development, 22(2), pp. 122-133, 2014.

[20] AlQahtany, A., Rezgui, Y. \& Haijiang, L., Architectural Engineering and Design Management. Architectural Engineering and Design Management, 9(3), pp. 176-194, 2013.

[21] Labonne, B., The Mining Industry and the Community: Joining Forces for Sustainable Social Development. Natural Resources Forum, 23(4), pp. 315-322, 1999.

[22] Allen, L.R. \& Beattie, R.J., The role of leisure as an indicator of overall satisfaction with Community Life. Journal of Leisure Research, 16(2), pp. 99-109, 1984.

[23] Miles, M.B. \& Huberman, M.A., Qualitative Data Analysis: An Expanded Sourcebook. Sage: London, UK, 1994.

[24] Morse, J.M., Barrett, M. \& Mayan, M., Verification Strategies for Establishing Reliability and Validity in Qualitative Research. International Journal of Qualitative Methods, 1(2), pp. 13-22, 2002.

[25] RMWB, Municipal Development Plan (Devel. Plan Bylaw No.11/027), 2011, Online. Retrieved from http://www.woodbuffalo.ab.ca/Assets/MDP+Assets/Draft_MDP/ Final+MDP.pdfopment.

[26] Government of Alberta, Highway 63, Alberta Transportation, 2015, Online. Retrieved from https://www.transportation.alberta.ca/4942.htm

[27] Regional Municipality of Wood Buffalo [RMWB]. The Municipal Census 2015 Report, 2015, Online. Retrieved from http://www.rmwb.ca/Assets/Corporate/ Census+Reports/Municipal+Census+2015+Report.pdf

[28] Cohen, N. \& Arieli, T., Field research in conflict environments: Methodological Challenges and Snowball Sampling. Journal of Peace Research, 48(4), pp. 423-435, 2011.

[29] Creswell, J.W., Qualitative Inquiry and Research Design: Choosing Among Five Approaches, Sage: Los Angeles, USA, 2012.

[30] Government of Alberta, Investing in Our Future: Responding to the rapid growth of oil sands development, Alberta Energy, 2006, Online. Retrieved from http://www.energy.alberta.ca/pdf/OSSRadkeReportInvesting2006.pdf

[31] Keough, S.B., Planning for Growth in a Natural Resource Boomtown: Challenges for Urban Planners in Fort McMurray, Alberta.Urban Geography, 36(8), pp. 1169-1196, 2015.

[32] Burley, D., Are the social and physical really so different? Elements in the development of an attachment to place. Paper presented at the Annual Meeting of the American Sociological Association, 2007. 